\title{
ПРОБЛЕМЫ ОБЕСПЕЧЕНИЯ ЭФФЕКТИВНОГО УПРАВЛЕНИЯ ВЗАИМООТНОШЕНИЯМИ С ЗАИНТЕРЕСОВАННЫМИ СТОРОНАМИ В ФАНДРАЙЗИНГОВОЙ ДЕЯТЕЛЬНОСТИ БЛАГОТВОРИТЕЛЬНОЙ ОРГАНИЗАЦИИ
}

\author{
(C) 2020 Басова Мария Михайловна \\ кандидат экономических наук, доцент \\ доцент Департамента учета, анализа и аудита \\ Финансовый университет при Правительстве Российской Федерации, Россия, Москва \\ E-mail: MMBasova@fa.ru
}

\begin{abstract}
Статья посвящена изучению основных проблем, возникающих в процессе взаимодействия благотворительных организаций с заинтересованными сторонами в процессе фандрайзинговой деятельности. В статье рассматриваются сложности и ставятся задачи по улучшению работы современных фандрайзеров в ракурсе эффективного управления взаимоотношениями со стейкхолдерами. В качестве одного из направлений деятельности фандрайзеров предлагается использовать реестр и план коммуникаций заинтересованных сторон с примером практической реализации на конкретных данных благотворительного фонда «Дети наши».
\end{abstract}

Ключевые слова: Благотворительные организации; благополучатели; благотворители; фандрайзинг; фандрайзинговая деятельность; фандрайзер; стейкхолдеры; реестр и план коммуникаций заинтересованных сторон.

Одним из основных способов устойчивого развития российских благотворительных организаций (БО) является их успешная фандрайзинговая деятельность - работа по привлечению финансовых и нефинансовых ресурсов, которая ведет к появлению качественно разнообразных форм взаимодействия с бизнес-структурами, частными жертвователями, органами государственной власти, а также с организациями и частными лицами, нуждающимися в помощи. В настоящее время в условиях конкуренции за «традиционные» ресурсы и в поисках новых каналов финансирования благотворительные организации должны постоянно оценивать эффективность своей фандрайзинговой работы [1].

Взаимодействие с заинтересованными сторонами в фандрайзинговой деятельности благотворительной организации необходимо, прежде всего, для ее эффективной работы и перспективного развития. Широко распространенным инструментом бизнес анализа, который целесообразно использовать в фандрайзинговой деятельности благотворительных организаций, является анализ стейкхолдеров, который позволит определить основные заинтересованные стороны, а также изучить предпочтительные направления взаимодействия с ними [2]. Под стейкхолдерами благотворительный фонд по- нимает группы людей, государственные органы, коммерческие и некоммерческие организации. Анализ фандрайзинговой деятельности ряда российских благотворительных организаций, позволил сделать вывод, что в настоящее время в России не сложилась устойчивая модель взаимодействия с заинтересованными лицами: отсутствует ясное понимание принципов взаимодействия стейкхолдеров с учетом обоюдных интересов, преобладает неформальная структура этих отношений, носящая неравноправный, нерегулярный и асимметричный характер.

Перечень стейкхолдеров фандрайзинговой деятельности определяется в рамках отдельных программ фонда или в разрезе отдельных программных мероприятий. По оценкам Центра управления благосостоянием и филантропии Московской школы управления СКОЛКОВО за 2019 год были выявлены следующие приоритеты благотворительной деятельности в России (таблица 1).

Данные таблицы 1 свидетельствуют о том, что предпочтительным направлением благотворительной деятельности в России является фандрайзинговая деятельность в сфере поддержки детей и их семей, находящихся в трудной жизненной ситуации. В этой связи, проблемы обеспечения эффективного управления взаимоот- 
Таблица 1. Основные приоритеты благотворительной деятельности в России

\begin{tabular}{|l|l|l|}
\hline \multicolumn{1}{|c|}{ Население в целом } & \multicolumn{1}{|c|}{ Топ-менеджеры компаний МСБ } & \multicolumn{1}{|c|}{ Владельцы капитала } \\
\hline 1. Дети (58\%) & 1. Дети (62\%) & 1. Дети (74\%) \\
\hline 2. Религиозные организации (30\%) & $\begin{array}{l}\text { 2. Малоимущие и социально не- } \\
\text { благополучные (49\%) }\end{array}$ & $\begin{array}{l}\text { 2. Малоимущие и социально не- } \\
\text { благополучные (50\%) }\end{array}$ \\
\hline 3. Малоимущие (28\%) & 3. Церковь и религия (26\%) & 3. Церковь и религия (28\%) \\
\hline 4. Животные (20\%) & 4. Образование и наука (14\%) & 4. Образование и наука (22\%) \\
\hline
\end{tabular}

Источник: составлена автором по данным Центра управления благосостоянием и филантропии Московской школы управления СКОЛКОВО, 2019 [9]

ношениями с заинтересованными сторонами рассмотрим на примере фандрайзинговой деятельности благотворительных фондов в области оказания помощи детям- сиротам. Прежде всего, на наш взгляд, при постановке этих проблем необходимо провести группировку стейкхолдеров. В частности, можно предложить следующие группы заинтересованных сторон:

- государство,

- благополучатели,

- благотворители (доноры),

- организации, обеспечивающие (осуществляющие информационно-технологическую, правовую поддержку фандрайзинговой деятельности).

Первая группа стейкхолдеров - органы государственной власти. В данном направлении речь идёт как о финансовой, так и нефинансовой поддержке (одобрение проектов, разрешение действовать и т.д.). Что касается финансовой помощи, то это государственные федеральные и президентские гранты. Так, например, благотворительному фонду «Дети наши», который работает с детьми-сиротам и детьми, оставшимся без попечения родителей, очень помогает Департамент образования в Смоленской области и департамент здравоохранения в Нижегородской области. Постоянным партнером фонда является Смоленское областное государственное бюджетное учреждение «Шаталовский детский дом». Уже не первый год фонд сотрудничает и с областным государственным бюджетным учреждением здравоохранения «Специализированный дом ребенка «Красный Бор». Смоленским областным государственным бюджетным учреждением «Реабилитационный центр для детей и подростков с ограниченными возможностями здоровья «Вишенки» и Смоленским областным государственным бюджетным учреждением «Социально-реабилитационный центр для несовершеннолетних «Дом милосердия» и другими. Сотрудничество Фонда с представителями региональных органов власти и руководителями детских учреждений позволяет учитывать региональную специфику, потребности детей и специалистов в каждом конкретном детском учреждении, и в зависимости от этого вести необходимую работу по совершенствованию программ и проектов Фонда.

Вторая и третья группы заинтересованных сторон формируют основу фандрайзинговой деятельности организации это - благополучатели (дети-сироты, их ближайшие родственники, учреждения для детей-сирот) и благотворители (коммерческие структуры, спонсоры, частные жертвователи и пр.).

Четвертая группа стейкхолдеров оказывает информационно-технологическую и правовую поддержку фандрайзинговой деятельности благотворительных фондов, формирует стратегические приоритеты, но не имеет на нее прямого воздействия (банковские структуры, телеоператоры, юридические партнеры, общество, СМИ).

Какие сложности и проблемы в фандрайзинговой деятельности благотворительных фондов возникают в части взаимодействия с заинтересованными сторонами?

Самая главная практическая проблема - отсутствие хорошо подготовленных специалистов в области фандрайзинга (специалистов, которые занимаются привлечением средств в некоммерческих организациях), и неправильно выбранный стиль их поведения при переговорах о пожертвовании. В деятельности современных фандрайзеров есть целый ряд сложностей и рисков, и прежде всего профессиональных и организационных. Эти трудности чаще всего заключаются в выстраивании максимально эффективного процесса управления, а также в привлечении внимания к деятельности со стороны бизнеса, государства, частных лиц в умении согласовывать интересы благотворителей с интересами благотворительной организации. Теория и практика отдельных организаций показыва- 
ет, что при поиске средств финансирования на конкретные программы или проект фандрайзер должен находить индивидуальный подход к каждой группе жертвователей и обеспечивать эффективное управления взаимоотношениями с различными группами заинтересованных сторон. Остановимся на этом более подробно.

Роль государства в благотворительной деятельности сводится к созданию благоприятного законодательного фонда (стоит отметить, что очень слабо), поддержке инфраструктурных социальных проектов в форме грантов и субсидий (доля которых в отношении НКО в России невысока). Проблемы современного фандрайзера в этой сфере заключаются в том, что он не всегда отслеживает происходящее, не всегда бывает в теме политики государства; довольно редко проводит мониторинг конкурсов на субсидии и гранты, ориентированный на выбор подходящего для своей некоммерческой организации; некачественно и несвоевременно готовит, и подает грамотные заявки на конкурсы.

Основными мотивами благотворительной деятельности компаний (бизнеса) являются: личные желания руководителя и экономические выгоды для компании. В условиях взаимодействия с бизнесом задача фандрайзера, должна сводиться к обеспечению сотрудничества на постоянной основе, т.е стабильного партнерства в области разработки и реализации программ. Так например, на протяжении 10 лет партнерами благотворительного фонда «Дети наши» становились компании из разных отраслей и сегментов: АНО «Корпоративная Академия Росатома» - поддержка акции «Дарите навыки вместо игрушек», «Союзмультфильм» - безвозмездное предоставление продукции для акций фонда, мастер-класс по мультипликации, профориентационная экскурсия в рамках выезда кружка «Юный мультипликатор», Декатлон Лефортово предоставление спортивного инвентаря и экипировки детям, участие в акциях фонда, Кафе «Шоколадница» - предоставление питания на безвозмездной основе детям-сиротам и детям, оставшимся без попечения родителей и др. Сотрудничество осуществляется в разных форматах, в зависимости от целей и возможностей компании:

- Благотворительное пожертвование от компании в поддержку одной из программ фонда;

- Совместная акция: фонд организует сбор средств, компания удваивает (утраивает? учетверяет?) результат;

- Со-маркетинговая акция, когда\% или фиксированная сумма с продажи специального продукта перечисляется в фонд;

- Перечисление в пользу фонда бюджетов на сувениры и корпоративные подарки;

- Организация специальных мероприятий для сотрудников и партнеров компании - аукционов, лотерей, ярмарок, пр.;

- Информационная поддержка работы фонда (распространение новостей фонда среди сотрудников).

В свою очередь, благотворительный фонд может:

- Провести лекции для сотрудников по правильной благотворительности: защита от мошенников, эффективное взаимодействие с фондами, особенности благотворительности в сиротской теме;

- Провести консалтинговые встречи для ключевых сотрудников, занимающихся корпоративной социальной ответственностью: цели и задачи КСО, что такое стратегия КСО и зачем она нужна, вовлечение сотрудников, построение правильных внешних и внутренних коммуникаций;

- Создать совместно с компанией концепцию ее работы в области благотворительности и план ее воплощения.

Сотрудничество с благотворительным фондом «Дети наши» дает компаниям следующие возможности:

- Позитивный PR (создание и поддержка имиджа социально ответственной компании, усиление HR-бренда);

- Развитие и усиление корпоративной культуры компании: сплочение сотрудников вокруг добрых дел, поддержка;

- Совместный ко-маркетинг: создание специальных продуктов с благотворительной составляющей, что положительно влияет на имидж компании и привлечение новых клиентов;

- Просто добрые дела.

В фонде «Дети наши» фиксируют рост интереса к теме детского сиротства по возрастающему количеству обращений со стороны компаний: просят проконсультировать, какие способы помощи существуют, как взаимодействовать с детскими домами, как организовать волонтерскую помощь. В 2019 году Фонд организовывал 
несколько внутренних обучающих семинаров по правилам вхождения в благотворительную историю.

Крупные частные фонды (фонд Дмитрия Зимина «Династия», благотворительный фонд В.Потанина, Общественный фонд Владимира Смирнова и др.) доходы которых порой сопоставимы по размерам с корпоративными вложениями, нередко вкладывают свои личные деньги в различные проекты (исторические памятники, фундаментальная наука, спорт, благотворительность, и т.д.). В основе этого лежит решение руководителя фонда. Они выдают гранты на основании заявок и конкурсов тем некоммерческим организациям, которые являются известными и эффективными. В этом направлении все зависит от руководителя фирмы или его заместителя, т.е. от того, кто принимает решения. Если предпринимателя интересуют (по каким-то причинам) конкретные проблемы, например, онкологические заболевания, то он вполне может принять решение о помощи соответствующим организациям. Он может поддержать целый медицинский центр, а может ограничиться покупкой дорогостоящих лекарств. Рассматривая деятельность фандрайзера, с этим потенциальным источником финансирования, можно отметить, что он не всегда находит подход к руководителю фонда, не всегда понимает его мотивацию, и в результате может и не заинтересовать руководителя фонда в положительном решении.

Другая, не менее важная проблема, заключается в том, что благотворители, включая государственные органы, просто не готовы помогать благотворительным фондам. Основные претензии, заключаются в том, что, по мнению заинтересованных сторон, тот или иной благотворительный фонд «ворует» у благополучателей деньги, тратит их на собственные нужды, а не на обещанные программы. Для разрешения данной проблемы, современный фандрайзер должен контролировать работу благотворительного фонда в части представления достоверной и «прозрачной» отчётности. Отчетность должна быть представлена на дизайнерски продуманном сайте, который также должен содержать средства интерактивного общения; раскрытие и распространение информации о миссии, текущей деятельности БО, а также средства обеспечения безопасности (использование шифрования и защищённых серверов).

Следующая группа проблем связана непо- средственно с благополучателями и прежде всего с самими детьми. Они - весьма своеобразные люди. Из-за особенностей их воспитания они зачастую не готовы быть благодарными, не говорят «спасибо», не ценят те усилия, которые прикладывает фонд, и воспринимают все старания как должное, так как привыкли, что их все жалеют. Интернатная система приучает к мысли, что если ты сирота, то тебе все должны. Бесконечные подарки и праздники от абсолютно незнакомых людей только вредят детямсиротам - они вырабатывают у них привычку ждать от жизни поблажек («ведь я же сирота!»), но не учат ставить цели и прилагать усилия, чтобы чего-то добиться. Подарки ценятся ребёнком только в том случае, если сделаны по-настоящему близким человеком; детям нужны родители и друзья, а не спонсоры. Нельзя не затронуть и следующую группу благополучателей, а именно, сами сиротские учреждениями. Здесь проблемы заключаются в том, что далеко не все учреждения готовы что-то менять в жизни своих подопечных. Очень часто данные заведения не заинтересованы в том, что им предлагает фонд, и не хотят внедрять проекты по социализации и адаптации. Им достаточно того, чтобы кто-то просто предоставил деньги, сделал ремонт, поставил плазменный телевизор. На наш взгляд, работа фандрайзера с благополучателями должна строиться по системе обратной связи и регулироваться внутренними положениями БФ.

С целью выявления и устранения разрывов интересов при организации фандрайзинговой деятельности, благотворительным фондам необходимо сопоставлять требования всех групп заинтересованных сторон с фактическими параметрами работы самого фонда и показывать возможные пути и способы ликвидации, выявленных конфликтов. С этой целью, на наш взгляд, в помощь фандрайзеру придет разработанный реестр и составленный план коммуникаций заинтересованных сторон. Реестр должен включать общие данные (характеристики) основных стейкхолдеров: категории, существенные интересы и требования, ожидания, степень влияния и заинтересованности, важность поддержания, действия и др. План коммуникаций - описывает заинтересованные стороны фандрайзинговой деятельности благотворительного фонда, со стороны их информационных потребностей и способов их удовлетворения. Таким образом, «Реестр и план коммуникаций» должен включать 
в себя список основных стейкхолдеров, с учетом их требований. На основе анализа представленных данных в реестре и плане коммуникаций стейкхолдеров фандрайзинговой деятельности фандрайзер делает соответствующие выводы и определяет дальнейшие пути в части эффективного управления заинтересованными сторонами.

В качестве примера, в таблице 2 приведен «Реестр и план коммуникаций заинтересованных сторон» в рамках проекта «Не разлей вода Смоленская область» благотворительного фонда «Дети наши».

Возможное нарушение баланса интересов благотворительный фонд «Дети наши» видит в следующих причинах: установление завышенных целей по привлечению пожертвований; недостаток ресурсов и времени на осуществление фандрайзинговой деятельности; отсутствии комплексной работы по взаимодействию с донорами; неточности в определении мотивов пожертвований и использовании дохода; отсутствии благодарностей для доноров. Для решения выявленных проблем и повышения эффективности фандрайзинговой работы благотворительному фонду «Дети наши» в области управления взаимоотношениями с заинтересованными сторонами может быть предложен следующий комплекс мер по их устранению.

С каждым уровнем (группой) заинтересованных сторон благотворительный фонд «Дети наши» должен взаимодействовать по разному, однако смысл един: фонд должен предоставлять прозрачную и достоверную отчетность отно-

Таблица 2. Реестр и план коммуникаций стейкхолдеров фандрайзинговой деятельности благотворительного фонда «Дети наши» в рамках проекта «Не разлей вода - Смоленская область»

\begin{tabular}{|c|c|c|c|c|}
\hline $\begin{array}{c}\text { Стейкхолдеры - } \\
\text { основные группы } \\
\text { заинтересованных } \\
\text { сторон }\end{array}$ & $\begin{array}{c}\text { Ожидания стейк- } \\
\text { холдера от про-- } \\
\text { граммы - перечень } \\
\text { ожидаемых резуль- } \\
\text { татов }\end{array}$ & $\begin{array}{c}\text { Проверка ожиданий } \\
\text { стейкхолдеров }\end{array}$ & $\begin{array}{c}\text { Причины возмож- } \\
\text { ного нарушения } \\
\text { баланса интересов } \\
\text { БФ и стейкхолдеров }\end{array}$ & $\begin{array}{c}\text { Способы устранения } \\
\text { разрыва (информа- } \\
\text { ционные потребно- } \\
\text { сти) }\end{array}$ \\
\hline \multicolumn{5}{|c|}{ Государство } \\
\hline $\begin{array}{l}\text { Органы государ- } \\
\text { ственной власти. } \\
\text { Контролирующие } \\
\text { органы: Министер- } \\
\text { ство юстиции }\end{array}$ & $\begin{array}{l}\text { Успешная реализа- } \\
\text { ция проекта: дости- } \\
\text { жение заявленных } \\
\text { в проекте показате- } \\
\text { лей, доказательства } \\
\text { эффективности про- } \\
\text { екта, направленные } \\
\text { на профилактику } \\
\text { повторных отказов } \\
\text { от детей, снижению } \\
\text { уровня социаль- } \\
\text { ного сиротства и } \\
\text { его профилактике, } \\
\text { психологической } \\
\text { помощи по сохра- } \\
\text { нению кровных } \\
\text { семей и развитию } \\
\text { профессиональ- } \\
\text { ного сообщества } \\
\text { специалистов сферы } \\
\text { защиты детства. }\end{array}$ & $\begin{array}{l}\text { Запросы органов } \\
\text { власти, в рамках } \\
\text { заключенных дого- } \\
\text { воров. }\end{array}$ & $\begin{array}{l}\text { Завышение требо- } \\
\text { ваний по снижению } \\
\text { уровня социального } \\
\text { сиротства. } \\
\text { Недостаточный } \\
\text { спектр услуг, оказы- } \\
\text { ваемых воспитан- } \\
\text { никам и выпускни- } \\
\text { кам детских домов. }\end{array}$ & $\begin{array}{l}\text { Своевременная, } \\
\text { полная, прозрачная } \\
\text { отчетность о реаль- } \\
\text { ных результатах }\end{array}$ \\
\hline \multicolumn{5}{|c|}{ Благополучатели Фонда } \\
\hline $\begin{array}{l}\text { Воспитанники и } \\
\text { выпускники детских } \\
\text { домов. } \\
\text { Близкие родствен- } \\
\text { ники, окружение } \\
\text { кровной семьи. } \\
\text { Принимающие } \\
\text { семьи (включая } \\
\text { кровные). }\end{array}$ & $\begin{array}{l}\text { Позитивные изме-- } \\
\text { нения в жизненной } \\
\text { ситуации. Восста- } \\
\text { новление связей с } \\
\text { кровными/некров- } \\
\text { ными родственни- } \\
\text { ками } \\
\text { Повышение уровня } \\
\text { образования }\end{array}$ & $\begin{array}{l}\text { Недостаточное } \\
\text { количество детей } \\
\text { переданных на } \\
\text { воспитание в семьи } \\
\text { и количество вы- } \\
\text { пускников детских } \\
\text { домов, которые ста- } \\
\text { новятся полноцен- } \\
\text { ными, успешными } \\
\text { гражданами. }\end{array}$ & $\begin{array}{l}\text { Недостаточное из- } \\
\text { учение специфики } \\
\text { проблемного поля } \\
\text { выпускников и объ- } \\
\text { ема оказываемой } \\
\text { им помощи }\end{array}$ & $\begin{array}{l}\text { Развернутая инфор- } \\
\text { мация о возмож- } \\
\text { ностях фонда по } \\
\text { оказанию помощи. } \\
\text { Анализ данных о } \\
\text { социальной адапта- } \\
\text { ции выпускников } \\
\text { Анализ данных о } \\
\text { числе детей, воспи- } \\
\text { тываемых в семьях. }\end{array}$ \\
\hline
\end{tabular}




\begin{tabular}{|c|c|c|c|c|}
\hline \multicolumn{5}{|c|}{ Благотворители Фонда } \\
\hline $\begin{array}{l}\text { Юридические лица } \\
\text { (Коммерческие } \\
\text { структуры) }\end{array}$ & $\begin{array}{l}\text { Укрепление имиджа } \\
\text { компании как соци- } \\
\text { ально ответственно- } \\
\text { го бизнеса } \\
\text { Достижение соци- } \\
\text { ально значимых } \\
\text { результатов } \\
\text { Устойчивость ре- } \\
\text { зультатов } \\
\text { Качественная отчет- } \\
\text { ность }\end{array}$ & $\begin{array}{l}\text { Регулярное предо- } \\
\text { ставление финан- } \\
\text { совой и содержа- } \\
\text { тельной отчетности; } \\
\text { Визиты доноров в } \\
\text { БФ для наблюдения } \\
\text { за его работой }\end{array}$ & $\begin{array}{l}\text { Неточность в опре- } \\
\text { делении мотивов } \\
\text { пожертвований } \\
\text { дохода; } \\
\text { Некоторые пред- } \\
\text { ставители бизнеса } \\
\text { хотят } \\
\text { шумного пиара } \\
\text { своей благотвори- } \\
\text { тельной } \\
\text { деятельности }\end{array}$ & $\begin{array}{l}\text { БФ отвечает за } \\
\text { своевременную, } \\
\text { полную, прозрач- } \\
\text { ную отчетность, а } \\
\text { также за просвеще- } \\
\text { ние коммерческих } \\
\text { структур («чего } \\
\text { реально, а чего не- } \\
\text { реально добиться», } \\
\text { «в какие долгосроч- } \\
\text { ные результаты } \\
\text { инвестируются их } \\
\text { средства» и др.) } \\
\text {. }\end{array}$ \\
\hline $\begin{array}{l}\text { Физические лица } \\
\text { (Частные лица) }\end{array}$ & $\begin{array}{l}\text { Частные мотивы } \\
\text { направленные на } \\
\text { снижение социаль- } \\
\text { ного сиротства в } \\
\text { стране, }\end{array}$ & $\begin{array}{l}\text { Интервью и финан- } \\
\text { совые ежемесячные } \\
\text { отчеты о собранных } \\
\text { средствах в ходе } \\
\text { проведенных меро- } \\
\text { приятий }\end{array}$ & $\begin{array}{l}\text { Неточности в опре- } \\
\text { делении мотивов } \\
\text { пожертвований } \\
\text { и использовании } \\
\text { дохода; }\end{array}$ & $\begin{array}{l}\text { БФ отвечает за } \\
\text { своевременную, } \\
\text { полную, прозрач- } \\
\text { ную отчетность, а } \\
\text { также за просвеще- } \\
\text { ние частных лиц }\end{array}$ \\
\hline \multicolumn{5}{|c|}{ Информационно-технологическая поддержка фандрайзинговой деятельности БФ } \\
\hline Социальные сети & \begin{tabular}{|l} 
Информирование \\
населения и других \\
заинтересованных \\
сторон об акциях и \\
программах БФ
\end{tabular} & $\begin{array}{l}\text { Комментарии в } \\
\text { социальных сетях }\end{array}$ & $\begin{array}{l}\text { Недостаточная ин- } \\
\text { формированность } \\
\text { о работе фонда и } \\
\text { проводимых им } \\
\text { акциях. } \\
\text { Недостоверные } \\
\text { данные. }\end{array}$ & $\begin{array}{l}\text { БФ отвечает за сво- } \\
\text { евременную, пол- } \\
\text { ную, прозрачную } \\
\text { отчетность, а также } \\
\text { за просвещение всех } \\
\text { заинтересованных } \\
\text { сторон }\end{array}$ \\
\hline $\begin{array}{l}\text { Банковские структу- } \\
\text { ры (с точки зрения } \\
\text { оказания услуг по } \\
\text { электронному пере- } \\
\text { воду средств). }\end{array}$ & \begin{tabular}{|l} 
Обеспечение \\
электронного сбора \\
пожертвований
\end{tabular} & $\begin{array}{l}\text { Отзывы, отчеты } \\
\text { фандрайзеров. }\end{array}$ & $\begin{array}{l}\text { Недостаточно про- } \\
\text { стые и доступные } \\
\text { технологические } \\
\text { решения для тех, } \\
\text { кто хочет помогать } \\
\text { детям. }\end{array}$ & $\begin{array}{l}\text { Фонд должен уси- } \\
\text { лить сайт в части } \\
\text { предложения про- } \\
\text { стых и доступных } \\
\text { решений для всех } \\
\text { категорий доноров, } \\
\text { кто хочет помогать } \\
\text { детям }\end{array}$ \\
\hline $\begin{array}{l}\text { Мобильные телео- } \\
\text { ператоры (с точки } \\
\text { зрения оказания } \\
\text { услуг по электрон- } \\
\text { ному переводу } \\
\text { средств). }\end{array}$ & $\begin{array}{l}\text { Обеспечение элек- } \\
\text { тронного сбора по- } \\
\text { жертвований. СМС }\end{array}$ & $\begin{array}{l}\text { Отзывы, отчеты } \\
\text { фандрайзеров. }\end{array}$ & $\begin{array}{l}\text { Недостаточно про- } \\
\text { стые и доступные } \\
\text { технологические } \\
\text { решения для тех, } \\
\text { кто хочет помогать } \\
\text { детям. }\end{array}$ & $\begin{array}{l}\text { Фонд должен уси- } \\
\text { лить сайт в части } \\
\text { предложения про- } \\
\text { стых и доступных } \\
\text { решений для всех } \\
\text { категорий доноров, } \\
\text { кто хочет помогать } \\
\text { детям }\end{array}$ \\
\hline
\end{tabular}

сительно финансов, предоставленных другими стейкхолдерами. Взаимоотношения участников фандрайзинговой деятельности благотворительных организаций должны быть доверительными и научно-обоснованными, построенными на основе проведения многочисленных исследований по социальной адаптации детей-сирот, в том числе выпускников и числе детей, воспитываемых в приемных/кровных семьях и др. Это автоматически требует в этом процессе усиление роли фандрайзера в части работы с различными категориями стейкхолдеров.

Задача любого фандрайзера сводится к росту числа потенциальных спонсоров и благотворителей. Для этого в своей деятельности он должен широко использовать современные методы привлечения денежных средств и других ресурсов; систематически проводить анализ рынка доноров; разрабатывать системы привилегий для доноров; выявлять интересы доноров, их ожидания и претензии к некоммерческой организации [2].

У любой благотворительной организации есть большое количество контактов с благотворителями, информацию о которых необходимо где-то хранить, учитывать и анализировать. 
Для эффективной системы взаимоотношений с благополучателями (донорами) в практике фандрайзинговой деятельности российские благотворительные фонды должны иметь и развивать некую базу данных. С помощью большого количества информации, которую позволяет хранить база данных, можно увеличить и лояльность доноров. Например, им можно предложить увеличить размер пожертвования, используя информацию о их предыдущих пожертвованиях.

Специализированных систем, решающих такие задачи, для благотворительных организаций сейчас не существует. Фонды вынуждены самостоятельно создавать сервисы под свои нужды или использовать подручные инструменты - таблицы в Excel или возможности сайта WordPress. Excel считается недостаточно надежным средством из-за большого объема ручного труда, а «самописные» системы завязаны на конкретных разработчиков, и их непросто интегрировать с другими инструментами - рассылками, бухгалтерией, платежными сервисами.

Другой вариант - использовать системы, изначально предназначенные для работы с заказчиками коммерческих организаций (CRM, Customer Relationship Management). Но адаптированные коммерческие решения не всегда полностью подходят для потребностей благотворительных организаций.

Благотворительный Фонд «Дети наши», столкнулся с теми же сложностями и решил разработать собственный продукт, но с прицелом на его распространение среди других благотворительных организаций. С этой целью в фонде идет разработка и внедение проекта автоматизированной базы данных доноров фонда DRM-системы (Donor Relationship Management) с последующим ее распространением в другие благотворительные фонды. Целью проекта является повышение эффективности работы БО в области управления взаимоотношениями с донорами, волонтерами, благополучателями через разработку отраслевого решения для автоматизации управления взаимоотношениями с донорами для НКО [10].

Таким образом, деятельность благотворительных организаций базируется на принципе надлежащего учета мнений и ответственного поведения по отношению ко всем заинтересо- ванным сторонам, которые имеют прямое и косвенное влияние на нее. Реализуя свою миссию и стратегию благотворительные организации в лице фандрайзера должны учитывать мнение всех стейкхолдеров, работа в тесном диалоге с заинтересованными сторонами позволяет ему быстрее узнавать об ожиданиях всех стейкхолдеров и общества в целом и своевременно реагировать на их запросы и повышать эффективность самой фандрайзинговой деятельности.

В настоящее время в России сложилась парадоксальная ситуация. С одной стороны, повышается спрос на специалистов внутри благотворительного сектора, растет количество и самих БО, в которых ощущается острая необходимость в фандрайзерах. Однако, для специалистовфандрайзеров, которые хотят овладеть не только основами этой деятельности, но и глубоко ее изучить, в России еще не создана система специального профессионального образования; знания в этой предметной области данные лица получают, участвуя во всевозможных семинарах и тренингах. С целью повышения образовательного уровня фандрайзеров и повышения эффективности их деятельности, необходимо создать систему специального профессионального их образования в ВУЗах России.

С другой стороны, далеко не все БО будут готовы и готовы в настоящее время брать на работу высокопрофессиональных специалистов ввиду их статуса, который необходимо будет поддерживать и финансово оправдывать. Для очень многих благотворительных организаций прием на работу таких специалистов будет являться и является непозволительной «роскошью». В этой связи, благотворительным организациям требуется проведение многочисленных экономических расчетов, доказывающих или опровергающих влияние профессионализма фандрайзеров на эффективность самой фандрайзиновой деятельности БО.

Эффективное управление взаимодействием с заинтересованными сторонами в процессе фандрайзинговой деятельности, решение и устранение выявленных проблем, позволит любой благотворительной организации не только упрочить свою репутацию, но и определить возможности для стратегического ее развития с учетом потребностей общества. 


\section{Библиографический список}

1. Басова М. М. Основные критерии эффективности фандрайзинга в российских НКО // Экономические науки. 2019. № 175. C. 154-162.

2. Басова М. М. Основные подходы к обеспечению сбалансированности интересов участников фандрайзинговой деятельности НКО // Экономические науки. 2019. № 176. С. 127-134.

3. Басова М.M. Особенности составления нефинансовой отчетности в социально ориентированных некоммерческих организациях // Вестник Московского университета им. С. Ю.Витте. Серия 1: Экономика и управление. 2017. № 3 (22). С. 50-53.

4. Возмилкина Е.Н. Фандрайзинг в социальной сфере // Научно-методический электронный журнал «Концепт».-2016. - Т. 11.- С. 4066-4070. [Электронный ресурс] - URL: http://e-koncept.ru/2016/86852.htm.

5. Корнеева И.Е. Фандрайзинг в российских некоммерческих организациях: результаты эмпирического исследования // Мониторинг общественного мнения: Экономические и социальные перемены. 2016 № 4 С. 48-66.

6. Общественное объединение и некоммерческие организации: деятельность и поддержка: монография / под ред. Т.Э. Петровой.-М.: ИНФРА-М, 2018.-118 с

7. Официальный сайт Российского союза предпринимателей и промышленников [Электронный ресурс: http://media.rspp.ru].

8. Официальный сайт Благотворительного Фонда «Дети наши», [Электронный ресурс] - URL: https://detinashi. $\mathrm{ru}$ (Дата обращения 28.05.2020).

9. Официальный сайт Московской школы управления «Сколково» [Электронный ресурc] - URL:: https:// school.skolkovo.ru/ (Дата обращения 11.06.2020)

10. Что такое DRM и как она поможет благотворительным организациям наладить работу? [Электронный реcypc] - URL: https://takiedela.ru/news/2018/03/14/drm// (Дата обращения 11.06.2020) 